\title{
LEONARDO FIGLIUOLO
}

A Razoável Duração do Processo no Brasil: A Dinâmica Observada na 4a Vara Especializada em Crimes de Uso e Tráfico de Entorpecentes da Comarca de Manaus - AM

UNIVERSIDADE DE SÃO PAULO

FACULDADE DE DIREITO

SÃO PAULO/SP 



\title{
LEONARDO FIGLIUOLO
}

A Razoável Duração do Processo no Brasil: A Dinâmica Observada na 4a Vara Especializada em Crimes de Uso e Tráfico de Entorpecentes da Comarca de Manaus - AM

\begin{abstract}
Dissertação apresentada à Banca Examinadora do Programa de Pós-Graduação em Direito da Faculdade de Direito da Universidade de São Paulo, como exigência parcial para obtenção do título de Mestre em Direito, na área de concentração de Direito do Estado, sob a orientação do Professor Dr. Rubens Beçak.
\end{abstract}

UNIVERSIDADE DE SÃO PAULO

FACULDADE DE DIREITO

SÃO PAULO/SP 
Autorizo a reprodução e divulgação parcial deste trabalho, por qualquer meio convencional ou eletrônico, para fins de estudo e pesquisa, desde que citada a fonte.

Catalogação da Publicação Serviço de Biblioteca e Documentação Faculdade de Direito da Universidade de São Paulo

FIGLIUOLO, LEONARDO A Razoável Duração do Processo no Brasil: A Dinâmica Observada na 4" Vara Especializada em Crimes de Uso e Tráfico de Entorpecentes da Comarca de Manaus - AM ; LEONARDO FIGLIUOLO ; orientador RUBENS BEÇAK -- São Paulo, 2019. 153 Dissertação (Mestrado - Programa de Pós-Graduação em Direito do Estado) - Faculdade de Direito, Universidade de São Paulo, 2019. 1. A razoável duração do processo. 2. prisão provisória. 3. excesso de prazo. 4. Lei de Drogas. I. BEÇAK, RUBENS, orient. II. Título. 


\title{
LEONARDO FIGLIUOLO
}

\section{A Razoável Duração do Processo no Brasil: A Dinâmica Observada na 4a Vara Especializada em Crimes de Uso e Tráfico de Entorpecentes da Comarca de Manaus - AM}

\begin{abstract}
Dissertação apresentada à Banca Examinadora do Programa de Pós-Graduação em Direito da Faculdade de Direito da Universidade de São Paulo, como exigência parcial para obtenção do título de Mestre em Direito, na área de concentração de Direito do Estado, sob a orientação do Professor Dr. Rubens Beçak.
\end{abstract}

Aprovada em:

Banca Examinadora:

Orientador: Professor Dr. Rubens Beçak

Professor(a) Membro

Professor(a) Membro

Professor(a) Membro 

Acreditamos ser possível reduzir os níveis de violência, salvar muitas vidas humanas, evitar muita dor inútil, e, finalmente, fazer o sistema penal desaparecer um dia, substituindo-o por mecanismos reais e efetivos de solução de conflitos. (Eugenio Raúl Zaffaroni). 



\section{AGRADECIMENTOS}

Ao Professor Rubens Beçak, pela orientação na presente dissertação de mestrado e pelas preciosas aulas no curso de Pós-Graduação;

Agradeço profundamente à paciência de minha família, pelo apoio incondicional às minhas aspirações acadêmicas, bem como pelos momentos de completa ausência, em que deixei de comparecer por estar isolado em meu mundo, estudando ou redigindo este trabalho.

Aos meus colegas e, mais que isso, amigos de trabalho, que também entenderam momentos em que estive ausente, em razão de aulas, seminários ou outras atividades acadêmicas, mas que sempre me incentivaram a permanecer firme na conclusão deste trabalho final.

Aos meus amigos, desde aqueles dos tempos de colégio, mas também os feitos durante a Graduação e, mais recentemente, na Pós-Graduação, pelas longas e profundas conversas sobre temas diversos, que me ajudaram aliviar momentos de tensão, assim como pela colaboração para a conclusão desta dissertação.

Aos servidores públicos, juiz, promotores e defensores públicos da $4^{\underline{a}}$ VECUTE e do Tribunal de Justiça do Estado pela fundamental colaboração na minha pesquisa. 



\section{RESUMO}

O direito à razoável duração do processo, inserido expressamente no ordenamento jurídico brasileiro a partir do advento da Emenda Constitucional 45/2004, já poderia ser inferido desde a incorporação da Convenção Americana de Direitos Humanos, bem como ser considerado um corolário da garantia do devido processo legal. Nesse contexto, surge o direito em que o indivíduo preso provisoriamente tem de que o seu processo seja julgado em um prazo razoável. Diversos são os tratados internacionais dos quais o Brasil é signatário e que vão na mesma linha, definindo que a privação de liberdade durante o processo deve ser a exceção e não a regra. Trata-se, portanto, de um uso abusivo da prisão provisória. A interpretação da garantia não pode restar somente à livre vontade dos aplicadores do direito, sendo necessária uma regulamentação legal efetiva da duração da prisão preventiva, por meio de prazos concretos nos quais o sujeito deverá ser posto em liberdade. Para verificar se há aplicação do que dispõem as normas que disciplinam o uso da prisão provisória, foi realizada pesquisa na $4^{a}$ Vara de Crimes e Uso e Tráfico de Entorpecentes sobre o uso da prisão provisória na criminalização das Drogas. O Objetivo da pesquisa é verificar se a garantia da duração razoável do processo está sendo respeitado quando há prisões provisórias na criminalização das drogas. Para tanto, foi realizada pesquisa documental em processos de tráfico de drogas. Identificou-se, ainda, que o controle judicial efetivo das prisões provisórias, bem como a celeridade processual e a obediência aos prazos legais, são práticas que reduzem significativamente os índices de violação a duração razoável do processo. Considera-se que uma reforma legislativa venha a reduzir a possibilidade de violação da duração do processo, principalmente nos casos em que réu permanece preso provisoriamente durante o processo. provisória.

Palavras-chave: processo penal; razoável duração do processo; prisão 



\begin{abstract}
The right to a reasonable length of proceedings, expressly inserted in the Brazilian legal system from the advent of Constitutional Amendment 45/2004, could already be inferred since the incorporation of the American Convention on Human Rights, as well as being considered a corollary of the guarantee of due process. In this context, the right arises in which the provisionally arrested individual has to be prosecuted within a reasonable time. There are several international treaties to which Brazil is a signatory and which follow the same lines, stating that deprivation of liberty during the process should be the exception rather than the rule. It is therefore an abusive use of provisional imprisonment. Interpretation of the guarantee cannot be left solely to the free will of law enforcers, but effective legal regulation of the length of pre-trial detention is required, by means of specific periods within which the subject is to be released. In order to verify whether the rules governing the use of provisional arrest are applied, research was conducted at the 4th Criminal Court and Narcotics Use and Trafficking on the use of provisional arrest in the criminalization of Drugs. The objective of the research is to verify if the guarantee of the reasonable duration of the process is being respected when there are provisional arrests in the criminalization of drugs. To this end, documentary research was conducted on drug trafficking processes. It was also identified that effective judicial control of provisional arrests, as well as procedural speed and compliance with legal deadlines, are practices that significantly reduce the rates of violation to the reasonable duration of the process. Legislative reform is considered to reduce the possibility of infringement of the length of the proceedings, especially in cases where the defendant remains provisionally arrested during the proceedings.
\end{abstract}

Keywords: criminal process; reasonable length of proceedings; provisional arrest. 



\section{SUMÁRIO}

INTRODUÇÃO.

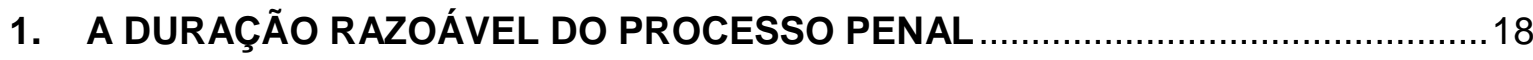

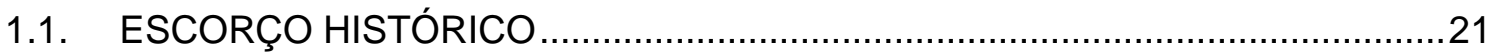

1.2. O DIREITO À DURAÇÃO RAZOÁVEL DO PROCESSO NO ORDENAMENTO

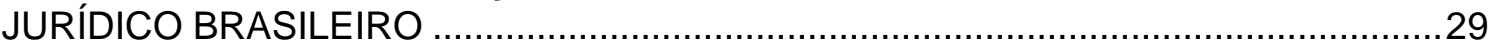

1.2.1. A Hierarquia da Convenção Americana de Direitos Humanos (Pacto de São José da Costa Rica) no Ordenamento Jurídico Brasileiro .........................................31

1.3. ANÁLISE DA EMENDA CONSTITUCIONAL № $45 / 2004 \ldots \ldots \ldots \ldots \ldots \ldots \ldots \ldots \ldots \ldots \ldots \ldots . . . . . . . . . . . . . . . . . . . .33$

1.3.1. Principais alterações da EC 45/04 em relação a razoável duração do

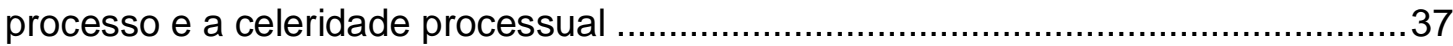

1.3.1.1. Aferição do merecimento pelos critérios objetivos de produtividade. ...37

1.3.1.2. Ininterrupção das atividades jurisdicionais e extinção das férias coletivas .38

1.3.1.3. Proporcionalidade do número de juízes em relação à demanda e à

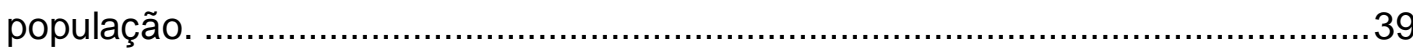

1.3.1.4. Despachos de mero expediente por servidores...................................39

1.3.1.5. Distribuição imediata de processos. ....................................................40

1.3.1.6. Demonstração de Repercussão Geral no Recurso Extraordinário. ......40

1.3.1.7. Súmulas Vinculantes...................................................................... 43

1.3.1.8. Informatização do processo judicial - Lei o 11.419/2006 _....................45

1.4. Duração razoável do processo penal e a garantia devido processo legal ..........48

2. A dURAÇÃo RAZOÁVEL DO PROCESSO PENAL NOS tRATAdOS INTERNACIONAIS DE DIREITOS HUMANOS ………….........................................51

2.1. O PACTO INTERNACIONAL SOBRE DIREITOS CIVIS E POLÍTICOS DE NOVA

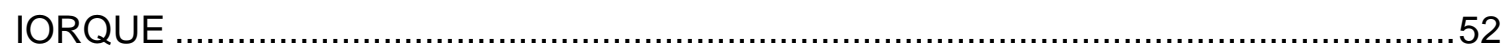

2.2. A CONVENÇÃO EUROPEIA DE DIREITOS HUMANOS....................................54

2.2.1. . Sistema Europeu de Proteção dos Direitos Humanos .................................57

2.2.2. Critérios adotados pelo Comissão Europeia de Direitos Humanos. .............59

2.3. Convenção Americana de Direitos Humanos. ..................................................62

2.4. CRITÉRIO ADOTADO PELO CORTE INTERAMERICANA DE DIREITOS

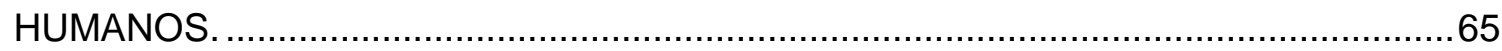

3. CONSEQUÊNCIAS DA VIOLAÇÃO DO DIREITO AO DIREITO DA RAZOÁVEL DURAÇÃO DO PROCESSO PENAL ...................................................................

3.1. RESPONSABILIDADE CIVIL DO ESTADO ………........................................

3.2. OUTRAS MEDIDAS NO DIREITO PENAL E PROCESSUAL PENAL .................72

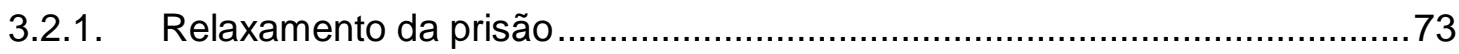

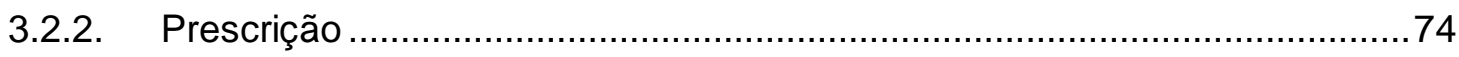

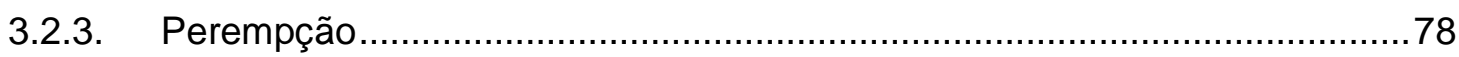




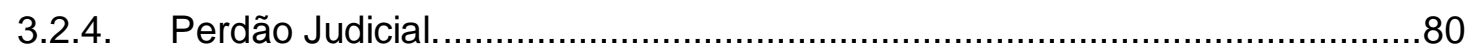

3.2.5. Extinção do Processo sem julgamento do mérito; ....................................81

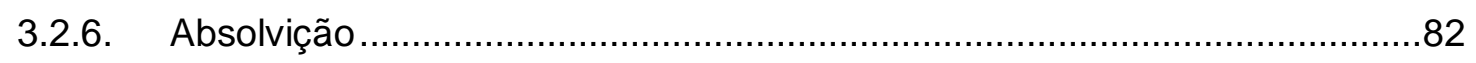

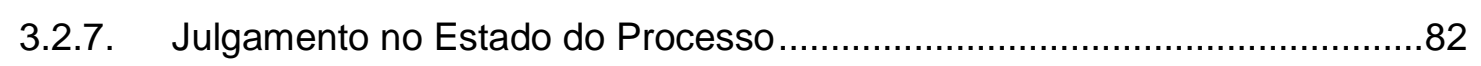

3.2.8. Atenuante Genérica - Art. 66 do CPB. ....................................................... 83

4. PRISÃO PROVISÓRIA E A RAZOÁVEL DURAÇÃO (PRAZO RAZOAVEL) ...........85

4.1. PRINCÍPIO DA PROPORCIONALIDADE ................................................90

4.2. PRAZO DA PRISÃO PROVISÓRIA NA ESPANHA, PORTUGAL, ALEMANHA E

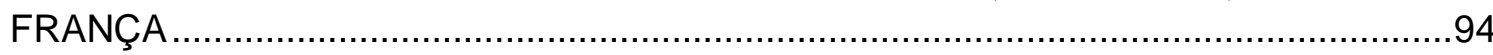

4.3. MODALIDADES DE PRISÃO PROVISÓRIA NO PROCESSO PENAL

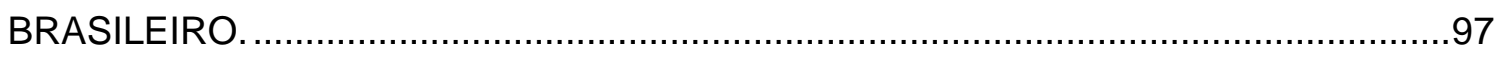

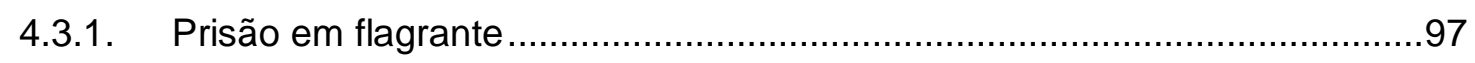

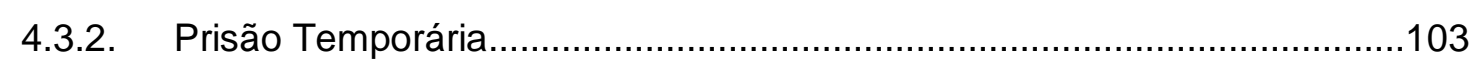

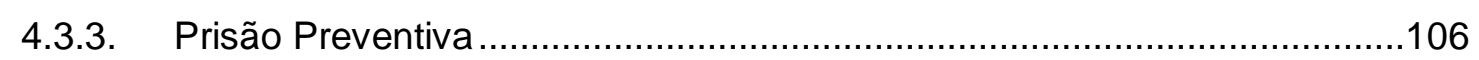

4.4. OS PRAZOS DA PRISÃO PROVISÓRIA NO PROCESSO PENAL BRASILEIRO: EVOLUÇÃO LEGISLATIVA E JURISPRUDENCIAL. ...........................................115

4.4.1. Critérios Adotados pelos tribunais pátrios para aferir a Duração Razoável da

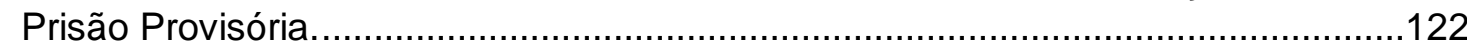

4.4.2. O comportamento processual do acusado e de sua defesa .......................125

4.4.3. A complexidade do caso .................................................................... 128

4.4.4. O comportamento das autoridades envolvidas ......................................130

5. A DURAÇÃO RAZOAVEL DO PROCESO NA 4a VECUTE ................................133

5.1. O EXCESSO DE PRAZO NA LEI DE DROGAS .........................................137

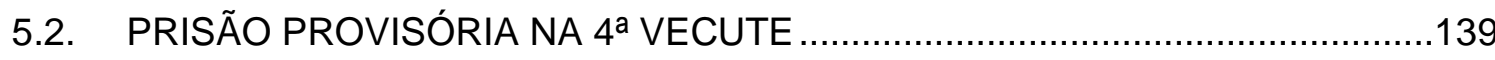

5.2.1. Insuficiência de controle judicial .........................................................139

5.2.2. Excesso de prazo...................................................................... 140

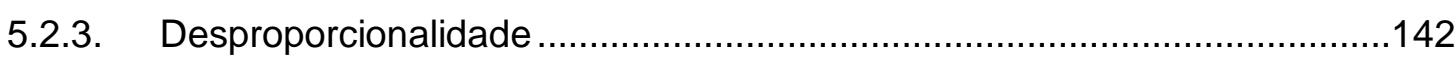

5.2.4. Antecipação de pena ..................................................................... 145

5.2.5. A armadilha do flagrante ............................................................... 145

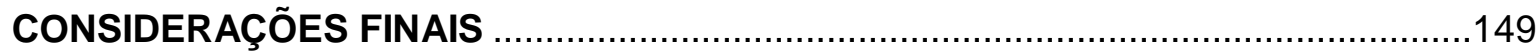

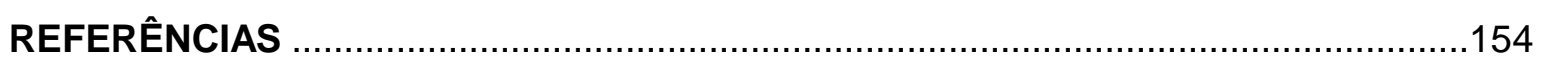




\section{INTRODUÇÃO}

O presente trabalho trata do direito a razoável duração do processo no processo penal. Derivado do princípio do devido processo legal e do acesso à justiça, e principalmente do princípio da dignidade da pessoa, surge a razoável duração do processo como garantia explícita em nossa Carta Constitucional, que diz respeito ao direito do cidadão à rápida prestação jurisdicional.

Já dizia Rui Barbosa: "mas justiça atrasada não é justiça, senão justiça qualificada e manifesta." É dizer a demora na resolução do processo significa a potencialização de um dano.

É sabido que o tempo é um dos pontos mais sensíveis do direito processual, principalmente nas medidas cautelares das prisões provisórias no direito processual penal, no qual se discute e analisa a liberdade do indivíduo. Por essa razão, essa temática vem se tornando objeto de grande preocupação por parte dos profissionais do direito, especificamente com o número excessivo de demandas levadas ao Judiciário.

Com a Emenda Constitucional no 45/2004, a Constituição Federal recebeu a inserção do princípio da razoável duração do processo no inciso LXXVIII do art. 5․ Tal princípio tem a função de promover a celeridade processual, fundamentando-se na efetividade da tutela jurisdicional, pois em diversas vezes o resultado que se espera do processo é excessivamente demorado.

No direito europeu, em decorrência da elevação à garantia constitucional, foi-se construindo uma sólida doutrina a respeito do âmbito normativo da razoável duração do processo, com implicações de diversos matizes, pois reconhecida sua importância para além das partes e do processo em si, afetando a comunidade como um todo.

No Brasil, antes mesmo da promulgação da EC № 45/04, vozes isoladas na doutrina nacional já se mostravam contrárias à demora processual e a dilação indevida, sustentando que era preciso se conferir dignidade constitucional ao princípio com o fito de se ampliar o campo de incidência dessa norma, porque ele não se restringia apenas ao processual. 
No entanto, é impossível encontrar soluções precisas, seguras e claras para o problema, em que pese a larga experiencia dos Tribunais e da doutrina com o princípio em exame.

A razoabilidade, no caso concreto, pode ser aferida pela complexidade da matéria discutida no processo, pelo comportamento das partes envolvidas na relação processual e pela atuação do órgão jurisdicional.

Diante dos fundamentos articulados, objetivo da pesquisa é verificar se a garantia da duração razoável do processo, está sendo respeitado quando há prisões provisórias na criminalização do tráfico de entorpecentes, analisar quais os critérios utilizados pela jurisprudência para caracterização do excesso de prazo na duração da prisão, assim como se há mecanismos que favorecem ou dificultam a observância dessa garantia. Para atingir esse objetivo foi desenvolvida uma pesquisa documental na $4^{a}$ Vara Especializada em Crimes de Uso e Tráfico de Drogas da Comarca de Manaus-AM.

O órgão judicial foi escolhido pelo fato de que a maior parte do presos provisórios no Brasil e especialmente em Manaus terem como réus presos provisoriamente pelos crimes tipificados na Lei de Drogas. Foram analisadas sentenças judiciais de processos julgados em relação aos crimes relacionados ao tráfico de drogas exaradas no ano 2018, que representa uma realidade recente e, ao mesmo tempo, suficiente para uma análise da observância da garantia da duração razoável duração do processo penal em relação a esses crimes citados.

O tema ora discutido é de tamanha importância que ganhou destaque em tratados internacionais sobre direitos humanos, o que demonstra preocupação internacional em relação ao assunto. Nesse sentido, o trabalho foi dividido em cinco capítulos.

No primeiro capítulo, expõem-se o surgimento e desenvolvimento da garantia. No segundo, analisa a garantia da duração razoável do processo no âmbito da declarações internacionais de direitos humanos. Na Europa, o princípio encontra aplicação prática nos Tribunais, designadamente desde 1953 com a entrada em vigor a convenção Europeia dos Direitos Homem (CEDH). O Tribunal Europeu dos Direitos Humanos (TEDH) tem jurisprudência no exame da matéria 
que influencia os Tribunais Constitucionais Europeus assim como a Corte Interamericana de Direitos Humanos.

No terceiro capitulo, analisa que a não observância, pelo próprio Estado, da garantia da razoável duração do processo e da celeridade pode implicar em responsabilidade civil do Estado pela demora na entrega da prestação jurisdicional, gerando direito à indenização pelos danos causados ao cidadão, bem como consequências processuais penais, tais como ao relaxamento da prisão por excesso de prazo, prescrição e o reconhecimento da atenuante genérica. No quarto, faz-se uma estudo sobre a legislação das prisões provisórias no Brasil e no Direito Comparado, assim como analisa os critérios utilizados pelos Tribunais Superiores para caracterização da violação da garantia estudada.

Por derradeiro, no último capítulo apresenta-se a pesquisa e os estudos realizados perante a $4^{\mathrm{a}}$ VECUTE.

Assim, o presente trabalho pretende dar sua contribuição para melhor conhecimento da justiça penal brasileira e o uso da prisão provisória na criminalização do tráfico de drogas. 


\section{CONSIDERAÇÕES FINAIS}

O princípio da razoável duração do processo em verdade é corolário da clausula do devido processo legal, assim antes mesmo de ser positivado em nosso ordenamento jurídico por meio da Emenda Constitucional 45/2004, implicitamente já consistia em mandamento a ser seguido pelas autoridades constituídas brasileiras responsáveis pelo tramite de processos administrativos e judiciais.

Com a aprovação da emenda, o aludido princípio passa tão somente a ser mais facilmente visualizado, contudo já se poderia entender a razoável duração do processo um consectário do devido processo legal. Pois, um processo devido é aquele que garante a ampla defesa, o contraditório, possui um juiz imparcial, é adequado do direito material que visa resolver, mas que igualmente possui uma duração razoável. A garantia tem um conteúdo direcionado à atividade jurisdicional, que deve ser efetivada em um lapso de tempo adequado e ajustado à realidade, com a finalidade de proteger os direitos fundamentais.

O Tribunal Europeu de Direitos Humanos assim como a Corte Interamericana de Direitos Humanos adotaram a teoria dos três critérios para determinar no caso concreto o prazo razoável da duração do processo, quais sejam: complexidade do caso, a atividade processual do interessado (imputado) e a conduta das autoridades judiciárias.

Esses três critérios têm sido sistematicamente invocados, tanto pelo Tribunal Europeu de Direitos Humanos, como também pela Corte Interamericana de Direitos Humanos para inferir se a garantia em questão foi ou não violada no caso concreto.

No presente trabalho, verificou-se que é possível ter consequências que vão além da responsabilização civil quando a garantia do razoável duração do processo é violado. No processo penal, por força da relevância do bem jurídico em questão, a indenização por vezes não será satisfatória.

Nesse sentido, na doutrina estrangeira as soluções sugeridas para a violação do direito na esfera penal têm sido muito variadas, tais como: aplicação de indulto; liberdade condicional; não execução da pena; redução da pena; aplicação 
de atenuante, remissão condicional da pena, reconhecimento de nulidade e prescrição.

No Brasil, a doutrina traz algumas soluções compensatórias no processo penal: Relaxamento de Prisão em caso de réu preso; Prescrição; Perempção; Perdão Judicial; Julgamento no Estado do Processo; Extinção do Processo sem julgamento do mérito; Absolvição e Atenuante Genérica - Art. 66 do CPB.

As medidas cautelares penais que atingem a liberdade individual, principalmente a prisão provisória, devem ser fixado prazo máximo para sua duração. Isto porque se trata de uma intervenção estatal na liberdade individual e como já dito é mais grave do que a própria prisão pena, pois nesta última houve atuação jurisdicional exaustiva com contraditório e ampla defesa, coberta pelo trânsito em julgado.

No âmbito das cautelares, o juízo é de mera probabilidade, na maioria absoluta das vezes decide-se sem ouvir o requerido. Não se pode olvidar ainda que, na realidade brasileira, as instituições que acolhem os presos provisórios são, em regra, mais indignas do que as destinadas aos condenados. Estes ainda podem ter progressão e regimes diferenciados enquanto a prisão cautelar é sempre em regime fechado.

Se por um lado não pode o legislador fixar um prazo máximo para a duração do processo porque este deve ser aferido em cada caso concreto, por outro deve fixar um prazo máximo para a prisão provisória e para as demais medidas cautelares, pois o princípio da legalidade não poderia atuar para a providência final (adstrito a um máximo de pena fixado pelo legislador) e ser desconsiderado para a providência provisória (cautelar).

Lamentavelmente a Lei 12.403/2011 não definiu os prazos de duração das medidas cautelares, diferentemente do que pretende o PL 156 (projeto de novo CPP), em trâmite no Congresso Nacional. A falta de previsão representa uma grave omissão legislativa, principalmente em relação aos prazos das prisões processuais e, por ora, deve ser suprida pela doutrina e jurisprudência.

No trabalho demonstrou-se que nos caso analisados a violação dos diversos aspectos que decorrem da razoável duração do processo em prisões 
provisórias aplicadas na criminalização das drogas ocorreram na grande maioria dos casos.

O controle judicial da prisão provisória é realizado principalmente na prisão em flagrante com criação das audiências de custódia. A excepcionalidade da prisão cautelar não é obedecida, já que em ocorre prisão em mais de $90 \%$ dos casos analisados.

A razoabilidade também não é observada, já que em mais de $50 \%$ por cento dos casos as prisões duram mais que os 180 dias previstos pela legislação brasileira. Na pesquisa verifica-se que a prisão não tem finalidade instrumental, ou seja, os motivos que influenciam na existência da prisão não são a garantia da ordem pública e da ordem econômica, a conveniência da instrução criminal ou a necessidade de assegurar a instrução criminal, mas a medida consiste em verdadeira antecipação da aplicação da sanção penal.

O que se revela muito grave é que a proporcionalidade entre a futura sanção e a medida cautelar não é observada, já que mais de $50 \%$ dos casos de criminalização das drogas em que houve prisão provisória resultam em uma pena em regime semiaberto ou em penas em regime aberto que, nos caso pesquisados, são convertidas em medidas alternativas à pena de prisão. Foi possível observar que há mecanismos estruturais que levam à violação sistemática do princípio da presunção de inocência.

Da forma como o sistema penal está estruturado, a possibilidade de a prisão provisória ocorrer na criminalização das drogas com violação aos seus princípios norteadores é muito grande, em especial quando se trata de réus que se enquadram no perfil de vulnerabilidade perante o sistema penal e nas localidades em que o controle judicial do flagrante não é efetivo. Os autores de crimes relacionados às drogas, em especial os que são flagrados praticando o ato, têm pouco poder de resistência ao sistema penal e encontram-se entre os setores mais vulneráveis à sua operacionalização seletiva, porque se enquadram no estereótipo de criminosos.

A prática de permitir a existência automática da prisão provisória sempre que há auto de prisão em flagrante, induz ao uso ilegítimo da prisão provisória por dois motivos principais. O primeiro deles é que muitas pessoas permanecem presas 
por inércia, ou seja, por simples falta de apreciação judicial sobre a necessidade da manutenção da prisão. Assim, muitas pessoas permanecem presas de semanas a meses. O segundo é que, após o controle judicial, se ocorreu o flagrante, sendo este homologados, os juízes têm maior tendência de converter a prisão em preventiva, principalmente se for preso em áreas de periferias.

Ao ser flagrada portando ou, simplesmente, estar em lugares considerados pontos de vendas drogas, a pessoa é presumivelmente considerada traficante e, nesse caso, imediatamente levada ao cárcere, mesmo que haja grande chance de que sua condenação seja diferente da pena privativa de liberdade, ou seja, absolvida, principalmente por falta de provas.

Se por esse novo motivo for processada, terá maior probabilidade de permanecer presa provisoriamente durante toda a instrução e de ser condenada a uma pena privativa de liberdade. Quando se verifica a lógica estrutural do sistema penal para quem pratica os crimes de tráfico de drogas, observa-se o quanto 0 sistema reforça a criminalização desses agentes e acaba retroalimentando o estereótipo criminal. As pessoas que no imaginário popular são as que mais praticam delitos acabam sendo aquelas mais presentes no sistema carcerário.

Observa-se que há mecanismos que exercem influência significativa na redução dos índices de violação do direito à razoável duração do processo na criminalização das drogas. $O$ mais eficiente é o controle judicial efetivo da prisão decorrente do flagrante logo após sua comunicação ao juiz competente. A criação das audiências de custódia deveria ser um meio bastante eficiente, no entanto a pesquisa revelou que mais $90 \%$ das flagrantes foram convertidas em prisões preventivas.

A celeridade e observância dos prazos processuais também contribuem para reduzir a violação dos princípios que regem a prisão provisória. A razoabilidade e a proporcionalidade estariam mais bem guardadas se a celeridade processual e a prática do relaxamento da prisão no caso de excesso de prazo fossem mais bem observadas. Estes dois mecanismos - controle judicial da necessidade e da razoabilidade da prisão provisória - não solucionam definitivamente o problema do uso indiscriminado da custódia cautelar na criminalização das drogas, mas reduzem a patamares menos graves a violação a garantia da razoável duração do processo. 
Porém, a manutenção da prisão provisória, por decisão influenciada pela ideologia da defesa social e impulsionada pela existência da prisão em flagrante, ainda é um problema que persiste mesmo quando esses mecanismos são adotados.

Outro fato importante é que problemas estruturais do Estado não são suficientes para justificar a demora na prestação jurisdicional, é dever do próprio Estado, inclusive do Poder Judiciário prestar um serviço digno.

Por outro lado, os estudos indicam que a reforma na legislação processual que permitisse um procedimento mais célere para aqueles réus presos provisórios denunciados por tráfico de drogas, mas que se inserissem nas condições do parágrafo $4^{\circ}$ do artigo 35 da lei de drogas ${ }^{229}$, impediria a existência de muitas prisões indevida por excesso de prazo. Uma reforma no procedimento da lei de drogas teria grande eficiência para a redução dos índices de réus presos provisoriamente por tráfico privilegiado.

A redução dos índices de violação da duração razoável do processo e do princípio da presunção de inocência pelo sistema penal na criminalização das drogas é uma meta que pode ser atingida, se houver um esforço dos órgãos judiciais nesse sentido, do mesmo, uma reforma legislativa garantindo procedimentos mais céleres sem perder de foco a garantia da ampla defesa e do contraditório. Enquanto esses fatos não se operam, a razoável duração do processo na prisão provisória continuará fazendo parte do discurso enquanto a realidade cada vez mais apresentará a antecipação da pena como regra.

${ }^{229}$ Art. 33. $\S 4^{\circ}$ Nos delitos definidos no caput e no $\S 1^{\circ}$ deste artigo, as penas poderão ser reduzidas de um sexto a dois terços, desde que o agente seja primário, de bons antecedentes, não se dedique às atividades criminosas nem integre organização criminosa. 


\section{REFERÊNCIAS}

AMARAL, Thiago Bottino do. A Súmula Vinculante Vincula? Um Estudo da Eficiência da Súmula Vinculante 24. Revista Brasileira de Ciências Criminais | vol. 143/2018, Maio / 2018 DTR\2018\12749.

ARRUDA, Samuel Miranda, Direito Fundamental à Razoável Duração do Processo. Brasília: Brasília Jurídica, 2006.

ÁVILA, Humberto Bergmann. "A distinção entre princípios e regras e a redefinição do dever de proporcionalidade", Revista de Direito Administrativo, n. 215, Rio de Janeiro: Renovar, 1999.

BADARÓ, Gustavo Henrique. Processo Penal, $3^{a}$ edição rev., atual. e ampl. São Paulo: Revista dos Tribunais, 2015.

Elsevier, 2008.

Direito Processual Penal, tomo I. Rio de Janeiro:

no prazo razoável. $2^{\mathrm{a}}$ ed. ver. atual. Rio de Janeiro: Lumens Juris, 2009.

BARROSO, Luís Roberto. Neoconstitucionalismo e constitucionalização do direito.

O triunfo tardio do Direito Constitucional no Brasil. Revista de Direito Constitucional e Internacional. vol. 58. p. 29-173. São Paulo: Ed. RT, jan.-mar. 2007.

BECCARIA, Cesare. Dos delitos e das penas. Trad. Por Torrieri Guimarães. São Paulo: Martin Claret, 2005.

BITENCOURT, Cezar Roberto. Tratado de Direito Penal. Parte Geral 1. 20르 ed. rev., ampl. e atual. São Paulo: Saraiva, 2014.

BRASIL. SUPERIOR TRIBUNAL DE JUSTIÇA. SÚMULA № 18. Disponível em: < http://www.sti.jus.br/SCON/sumulas/enunciados.jsp >. Acesso em: 19 dez. 2018.

CANOTILHO, J.J. Gomes. Direito Constitucional e teoria da Constituição, $4^{\mathrm{a}}$ edição editora Coimbra Almedina, ano 2000.

CHOUKR, Fauzi Hassan. Temas de direito e processo penal. Rio de Janeiro: Lumen Juris , 2004.

CINTRA, Antônio Carlos de Araújo; DINAMARCO, Cândido Rangel; GRINOVER, Ada Pellegrini. Teoria geral do processo. $30^{\mathrm{a}}$. ed. São Paulo: Malheiros Editores, 2014.

CRUZ, Rogério Schietti. Prisão cautelar. Dramas, Princípios e Alternativas. 4a edição, revista, atualizada e ampliada. Salvador: Jus Podvium, 2018.

DANTAS, Paulo Roberto de Figueiredo. Curso de Direito Constitucional, $2^{2}$ edição. São Paulo: Atlas, 2013.

DE MORAES, Alexandre. Direito Constitucional. 30ª edição. São Paulo: Atlas, 2014.

FONSECA, Vitor. Processo Civil e Direitos Humanos. São Paulo: Editora Revista dos Tribunais, 2018.

GIACOMOLLI, Nereu José. O devido processo penal: abordagem conforme a Constituição Federal e o Pacto de São José da Costa Rica: cases da Corte 
Interamericana, do Tribunal Europeu e do STF. 3로 edição. São Paulo: Gen/Atlas, 2017.

cárcere. São Paulo: Marcial Pons, 2013.

GOMES, Luiz Flávio et al. Prisão e medidas cautelares: comentários à Lei 12.403/11. São Paulo: Ed. RT, 2011.

GOMES, Luiz Flavio. Nova Lei de Drogas Comentada. São Paulo: RT, 2006.

GOMES FILHO, Antônio Magalhães. A motivação das decisões penais. São Paulo: Ed. Revista dos Tribunais, 2001. p. 32-34.

GOMES FILHO, Antônio Magalhães. Medidas cautelares e princípios constitucionais - comentários ao art. 282 do CPP, na redação da Lei no 12.403/2011. In: FERNANDES, Og (Org.). Medidas cautelares no processo penal: prisões e suas alternativas.

GRINOVER, Ada Pellegrini. As nulidades no processo penal. 11ª edição. São Paulo: RT, 2009.

GUERRA FILHO, Willis Santiago. Notas sobre algumas recentes inovações no perfil constitucional do Poder Judiciário. In: TAVARES, André Ramos; LENZA, Pedro; ALARCÓN, Pietro de Jesús Lora (Coord.). Reforma do Judiciário analisada e comentada. São Paulo: Editora Método, 2005.

HAMILTON, Sergio Demoro. A Razoável Duração do Processo e seus Reflexos no Processo penal. In: LIMA, Polastri Marcellus; SANTIAGO, Nestor Eduardo Arauna. (Cordenadores). A Renovação Processual Penal após a Constituição de 1988. Estudos em Homenagem ao Professor José Barcelos de Souza. Rio de Janeiro: Editora Lumen Juris, 2009.

JOBIM, Marcos Félix. Direito à Razoável Duração do Processo: Responsabilidade Civil do Estado em Decorrência da Intempestividade Processual. São Paulo: Conceito Editorial, 2011.

KOEHLER, Frederico Augusto Leopoldino. A razoável duração do processo. $2^{\underline{a}}$ ed. rev., ampl. e atual. Salvador: Juspodivm, 2013.

A Jurisprudência da Corte Europeia de Direitos

Humanos como Paradigma para a concretização do conceito de razoável duração do processo. Direito Federal. Revista da Ajufe. Ano 28 - número 95, 2ํㅗㄴ Semestre de 2015. São Paulo: Letras Jurídicas. 2015.

LOPES JÚNIOR, Aury. Direito Processual Penal. 15aa edição. São Paulo: Saraiva, 2018.

Prisões cautelares. 5a edição. São Paulo: Saraiva, 2017.

; BADARÓ, Gustavo Henrique Ivahy. Direito ao processo penal no

prazo razoável. 2ª ed. ver. atual. Rio de Janeiro: Lumens Juris, 2009.

LOPES, Dimas Ferreira. Celeridade do processo como garantia constitucional estudo histórico comparativo: constituições brasileira e espanhola. In. FIUZA, César (Org.). direito processual na história. Belo Horizonte: Mandamentos, 2002.

MACIEL, Adhemar Ferreira. "O devido processo legal e a Constituição brasileira de 1988". RePro 85/175 (DTR\1997\82)-180, São Paulo: RT, jan.-mar. 1997. 
MARINONI, Luiz Guilherme. MITIDEIRO; Daniel. Repercussão geral no recurso extraordinário - São Paulo: Editora Revista dos Tribunais, 2007.

MARINONI, Luiz Guilherme. Garantia da tempestividade da tutela jurisdicional e duplo grau de jurisdição. In: Garantias constitucionais do processo civil, 1를 edição. Coord. Jose Rogério Cruz e Tucci. São Paulo: Revista do Tribunais, 1999.

MAUÉS, Antônio Moreira. Supralegalidade dos Tratados Internacionais de Direitos Humanos e Interpretação Constitucional. Revista Internacional de Direitos Humanos, vol. 10, n. 18, Jun. 2013.

MARQUES, José Frederico. Elementos de direito processual penal. $3^{\underline{a}}$ ed. rev. e atual. por Eduardo Reale Ferrari e Guilherme Madeira Dezem. Campinas: Millenium, 2009, v. 4. p.53.

MAZZUOLI, Valério de Oliveira. O sistema regional europeu de proteção dos direitos humanos. Cadernos da Escola de Direito e Relações Internacionais, Curitiba, v. 1, n. 13, 2010.

MENDES, Gilmar Ferreira; FUCK, Luciano Felício. Novo CPC e o Recurso Extraordinário. Revista de Processo, vol. 261/2016, p. 263 - 279, Nov / 2016.

MENDONÇA, Andrey Borges de. Prisão cautelar e outras medidas cautelares pessoais. São Paulo: Método, 2011.

NICOLLIT, André. A Duração Razoável do Processo. São Paulo: Ed. Revista dos Tribunais, 2 ${ }^{\mathrm{a}}$ ed. 2014.

Tribunais, 6를 2016.

Manual de Processo Penal. São Paulo: Ed. Revista dos

Processo Penal Cautelar: Prisão e demais Medidas Cautelares.

São Paulo: Ed. Revista dos Tribunais, $2^{\mathrm{a}}$ ed. 2015.

NUCCI, Guilherme de Souza. Manual de Processo Penal. São Paulo: Ed. RT, $2^{\underline{a}}$ ed. 2011.

PACELLI, Eugênio; COSTA, Domingos Barroso da. Prisão Preventiva e Liberdade Provisória. A Reforma da Lei no 12.403/11. São Paulo: Editora Atlas, 2013.

Paulo: Atlas, 2014.

Curso de Processo Penal. 18. ed. rev., atual., e ampl. São

PASTOR, Daniel Roberto. El plazo razonable en el proceso del estado de derecho: una investigación acerca del problema de la excesiva duración del proceso penal y sus posibles soluciones. Buenos Aires: Ad Hoc. 2009.

PINTO, Ana Luíza. A Celeridade no Processo Penal: O Direito à Decisão em Prazo Razoável. Ed. Coimbra. 2008.

PIOVESAN, Flávia. Direitos Humanos e o Direito Constitucional Internacional. $4^{\text {a }}$ ed. São Paulo: Max Limonad, 2000.

PIOVESAN, Flávia. Direitos Humanos e o direito constitucional internacional. 11aㅡ ed. São Paulo: Saraiva, 2010. 
REIS, Marcelo Terra. Tempestividade da prestação jurisdicional como direito fundamental. In: Teixeira, Anderson Vichinkeski; LONGO, Luiz Antônio. A constitucionalização do direito. Porto Alegre: Sergio Antônio Fabris, 2008.

ROSA, Alexandre Morais da, Guia Compacto do Processo Penal conforme a teoria dos jogos 2 ${ }^{\text {a }}$ Ed. Lumens Juris, Rio de Janeiro, 2014.

SANGUINÉ, Odone. Efeitos perversos da prisão cautelar. Revista Brasileira de Ciências Criminais. n. 86. São Paulo: Ed. RT. set./out. 2010.

SILVA, Ivan de Oliveira. Filosofia do Direito. São Paulo: Atlas, 2010.

SILVA, José Afonso da. Curso de Direito Constitucional positivo. 37a . ed. rev. e atual. São Paulo: Malheiros, 2014.

SILVA, José Afonso. Prefácio. In: CASTRO, Carlos Roberto Siqueira. O devido processo legal e os princípios da razoabilidade e da proporcionalidade. 3. ed. Rio de Janeiro: Forense, 2005.

SILVEIRA, Paulo Fernando. Devido processo legal. 3‥ Ed. Belo Horizonte, 2001. TAVARES, André Ramos. Reforma do Judiciário no Brasil pós-88: (des)estruturando a justiça: comentários completos à EC n. 45-04. São Paulo: Saraiva, 2005.

Paulo: Saraiva. 2014.

Curso de Direito Constitucional. $12^{\mathrm{a}}$ edição. São Lenza, Pedro. Alarcon, Pietro de Jesus Lora. Reforma do Judiciário Analisada e Comentada. 1ํㅡㄹ Edição. Editora Método, 2005.

TOURINHO FILHO, Fernando da Costa, Manual de Processo Penal.16ª edição. São Paulo: Saraiva. 2013.

TUCCI, José Rogério Cruz e. Garantia do Processo sem Dilações Indevidas. Garantia Constitucionais do Processo Civil. São Paulo: RT, 1999.

Garantia da Prestação Jurisdicional sem Dilações Indevidas como Corolário do Devido Processo Legal. Revista de Processo, a.17, n. 66, abriljunho de 1992.

TUCCI, Rogério Lauria. Direitos Garantias Individuais no Processo Penal Brasileiro. 4" Edição. São Paulo: Revista do Tribunais, 2011.

WOLKMER, Antônio Carlos. O Direito nas Sociedades Primitivas. In: (Org.). Fundamentos da História do Direito. 4a ed. Belo Horizonte: Del Rey, 2007.

ZAFFARONI, Eugenio Raul; PIERANGELI, Jose Henrique. Manual de direito penal brasileiro. 9a ed. rev. e. ampl. São Paulo: Ed. Revista dos Tribunais, 2011. v.1

\section{LEGISLAÇÕES}

BRASIL. Constituição da República Federativa do Brasil de 1988. Disponível em: http://www.planalto.gov.br/ccivil_03/constituicao/constituicaocompilado.htm > Acesso em nov/2018.

BRASIL. Decreto Legislativo de 27, de 26 de maio de 1992. Aprova o texto da Convenção Americana sobre Direitos Humanos (Pacto São José) celebrado em 
São José da Costa Rica, em 22 de novembro de 1969, por ocasião da Conferência especializada Interamericana sobre Direitos Humanos. Disponível em: http://www2.camara.leg.br/legin/fed/decleg/1992/decretolegislativo-27-26-maio$1992>$ Acesso em nov/2018.

CONSTITUCIÓN ESPAÑOLA. Congreso de los Disputados. Disponível em: http://www.congreso.es/consti/constitucion/indice/titulos/articulos.jsp?ini=15\&fin=2 9\&tipo $=>2$ Acesso em: 10 de janeiro de 2019.

Constituição da República Portuguesa. Disponível em: https://dre.pt/legislacaoconsolidada/-/lc/34520775/view > Acesso em: 10 de janeiro de 2019.

CONVENÇÃO AMERICANA SOBRE OS DIREITOS HUMANOS (PACTO DE SÃO JOSÉ DA COSTA RICA). Documentos Básicos em Matéria de Direitos Humanos no Sistema Interamericano. Disponível em: http://www.cidh.oas.org/basicos/ portugues/c.Convencao_Americana.htm Acesso em: 02 de abril de 2018.

CONVENÇÃO PARA A PROTEÇÃO DOS DIREITOS DO HOMEM E DAS LIBERDADES FUNDAMENTAIS. In European Court of Human Rights. Disponível em: http://www.echr.coe.int/Documents/Convention POR.pdf Acesso em: 02 de abril de 2018.

COSTITUZIONE DELLA REPUBBLICA ITALIANA. Governo Italiano. Governo Italiano. Disponível em: http://www.governo.it/Governo/Costituzione/principi. html Acesso em: 10 de novembro de 2018. 